\title{
PRODUÇÃO DE PROTEÍNA UNICELULAR A PARTIR DO BAGAÇO DE MAÇÃ UTILIZANDO FERMENTAÇÃO EM ESTADO SÓLIDO
}

\section{PRODUCTION OF SINGLE CELL PROTEIN FROM APPLE POMACE USING STATE SOLID FERMENTATION}

\footnotetext{
Francielo Vendruscolo ${ }^{1}$; Fernanda $\mathrm{Koch}^{2}$; Luana de Oliveira Pitol ${ }^{3}$; Jorge Luiz Ninow ${ }^{4}$ ${ }^{1}$ Universidade Federal Santa Catarina - UFSC - Florianópolis - Brasil francielo@enq.ufsc.br ${ }^{2}$ Universidade Federal de Santa Catarina-UFSC - Florianópolis - Brasil fekoch@bol.com.br ${ }^{3}$ Universidade Federal de Santa Catarina - UFSC - Florianópolis - Brasil luanapl@ hotmail.com

${ }^{4}$ Universidade Federal de Santa Catarina - UFSC - Florianópolis - Brasil jorge@enq.ufsc.br
}

\section{Resumo}

Neste trabalho o bagaço de maçã foi utilizado como substrato para a produção de proteína unicelular através da fermentação em estado sólido, onde o fungo filamentoso Gongronella butleri CCT4274 foi empregado no enriquecimento protéico deste resíduo. Na fermentação em estado sólido, após estudar a influência da adição de fontes de nitrogênio, umidade inicial $e$ granulometria sobre a produção de proteína solúvel, obteve-se um enriquecimento protéico de 2,5 vezes sobre o teor protéico inicial do resíduo, chegando a produzir 19,24\% de proteína solúvel na melhor condição de cultivo verificada: uréia a $5 \%(\mathrm{p} / \mathrm{p})$ como fonte de nitrogênio, unidade inicial de $70 \%$ e a granulometria na faixa de 0,85 a 1,70mm.

Palavras chaves: bagaço de maçã; proteína solúvel; fermentação em estado sólido (FES).

\section{Introdução}

Muitos microrganismos apresentam capacidade de crescimento em substratos sólidos, sendo os fungos filamentosos os mais utilizados, devendo-se esta aplicação pela capacidade de crescimento na ausência de água livre, versatilidade de aplicação e manipulação (BALASUBRAMANIEM et al.,2001; DEL BIANCHI et al., 2001). O uso destes microrganismos como suplemento ou substituto alimentar mostra-se vantajoso, já que se multiplicam rapidamente e possuem alta concentração de aminoácidos essenciais, além de enriquecerem o substrato onde são cultivados com enzimas e vitaminas (ANUPAMA e RAVINDRA, 2000; MARTINS et al., 2002).

O estado de Santa Catarina por ser o maior produtor nacional de maçãs, produzindo aproximadamente 400 mil toneladas por ano, gera grandes quantidades de resíduos sólidos. 
Atualmente, estes resíduos são usados como adubo orgânico em lavouras e como ração animal, embora seu conteúdo protéico seja baixo (VILLAS-BÔAS et al., 2002). Por possuir elevado teor de açúcares, o bagaço de maçã pode ser uma alternativa para utilização como substrato não convencional para microrganismos (BEROVIC e OSTROVERSNIK, 1997). Diante disso, o presente trabalho teve como objetivo o enriquecimento protéico do bagaço de maçã utilizando o processo de fermentação em estado sólido.

\section{Materiais e métodos}

O microrganismo utilizado foi o fungo filamentoso Gongronella butleri CCT 4274, obtido da Coleção de Culturas Tropicais da Fundação "André Toselo" (Campinas - SP), mantido em ágar PDA (Ágar Batata Dextrose) a $4^{\circ} \mathrm{C}$.

\subsection{Meio de Cultivo}

O substrato utilizado foi o bagaço de maçã adicionado da fonte de nitrogênio, autoclavado a $121^{\circ} \mathrm{C} / 15$ min e inoculado com $4 \times 10^{6}$ esporos. meio $^{-1}$. A temperatura de incubação foi $30^{\circ} \mathrm{C}$, a aeração de $0,4 \mathrm{~L} \cdot \mathrm{min}^{-1}$.coluna ${ }^{-1}$ e o tempo de cultivo de 7 dias. Foram realizados dois planejamentos experimentais fatoriais $2^{2}$ para avaliar a fonte de nitrogênio (nitrato de sódio e uréia) e sua concentração ( 2 e $5 \%$ p/p), umidade inicial (60 e 70\%) e granulometria $(+0,85-1,70$ e $+1,70$ $3,35 \mathrm{~mm}$ ) do meio de cultivo no enriquecimento protéico do bagaço de maçã.

\subsection{Determinações Analíticas}

Neste trabalho foi determinado o conteúdo de proteína solúvel pelo método de LOWRY et al. (1951), o consumo de açúcares redutores segundo método do ácido 3,5-dinitrosalicílico conforme descrito por MILLER (1959) e umidade segundo metodologia proposta pela AOAC (1995).

\section{Resultados e discussão}

A Tabela 1 apresenta a matriz do primeiro planejamento experimental fatorial $2^{2}$ com as variáveis codificadas, variáveis reais e as respostas proteína solúvel e redução no conteúdo de açúcares redutores no bagaço de maçã. 
Tabela 1- Variáveis codificadas, variáveis reais e respostas para o primeiro planejamento fatorial $2^{2}$.

\begin{tabular}{lllllll}
\hline & \multicolumn{2}{l}{ Var. Codificadas } & Var. Reais & \multicolumn{2}{l}{ Respostas } \\
\hline Exp. & FN & CFN & FN & CFN (\%) & PS (\%) & RAR (\%) \\
\hline 1 & -1 & -1 & NaNO $_{3}$ & 2 & $13,71 \pm 0,42$ & $48,26 \pm 2,48$ \\
2 & -1 & +1 & $\mathrm{NaNO}_{3}$ & 5 & $14,96 \pm 0,26$ & $53,86 \pm 0,83$ \\
3 & +1 & -1 & Uréia & 2 & $14,80 \pm 0,50$ & $53,61 \pm 2,53$ \\
4 & +1 & Uréia & 5 & $17,99 \pm 0,29$ & $64,71 \pm 0,45$ \\
\hline
\end{tabular}

FN: fonte de nitrogênio; CFN: Concentração da fonte de nitrogênio; PS: Proteína solúvel; RAR: Redução de açúcares redutores.

Analisando a Tabela 1, pode-se verificar que o experimento 4, utilizando a uréia na concentração de $5 \%$ produziu maior quantidade de proteína solúvel e maior redução no conteúdo de açúcares redutores do bagaço de maçã quando comparado aos demais experimentos, atingindo valores de $17,99 \%$ e $64,71 \%$.

A Tabela 2 apresenta a estimativa dos efeitos dos fatores fonte de nitrogênio e concentração da fonte de nitrogênio sobre a produção de proteína solúvel.

Tabela 2- Estimativa dos efeitos e valores de p para a resposta proteína solúvel.

\begin{tabular}{lll}
\hline & Efeito & Valor de p \\
\hline Média & 15,3625 & 0,0000 \\
Fonte de nitrogênio & 2,0600 & 0,0093 \\
Concentração & 2,2200 & 0,0072 \\
Fonte de nitrogênio X Concentração & 0,975 & 0,0905 \\
\hline
\end{tabular}

Analisando a Tabela 2, pode-se verificar que os fatores fonte de nitrogênio e sua concentração apresentaram efeito significativo $(\mathrm{p}<0,05)$ sobre a produção de proteína solúvel. A variável fonte de nitrogênio aumenta em média $2,06 \%$ a produção de proteína solúvel quando utilizada em seu nível superior (uréia). O aumento da concentração da fonte de nitrogênio de 2 para $5 \%$, aumenta em média 2,22\% o conteúdo de proteína solúvel.

A Tabela 3 apresenta a matriz do segundo planejamento experimental fatorial $2^{2} \mathrm{com}$ as variáveis codificadas, variáveis reais e as respostas proteína solúvel e redução no conteúdo de açúcares redutores no bagaço de maçã. 
Tabela 3- Variáveis codificadas, variáveis reais e respostas para o segundo planejamento fatorial $2^{2}$.

\begin{tabular}{lllllll}
\hline & \multicolumn{2}{l}{ Var. Codificada } & Var. Reais & \multicolumn{3}{l}{ Respostas } \\
\hline Exp. & Um. & Gran. & Um. (\%) & Gran. (mm) & PS (\%) & RAR (\%) \\
\hline 1 & -1 & -1 & 60 & $+0,85-1,70$ & $16,21 \pm 0,47$ & $53,53 \pm 1,06$ \\
2 & -1 & +1 & 60 & $+1,70-3,35$ & $15,32 \pm 0,50$ & $54,81 \pm 0,73$ \\
3 & +1 & -1 & 70 & $+0,85-1,70$ & $19,24 \pm 0,34$ & $66,79 \pm 0,52$ \\
4 & +1 & 70 & $+1,70-3,35$ & $17,35 \pm 0,40$ & $58,86 \pm 1,28$ \\
\hline
\end{tabular}

Um: umidade inicial; Gran: Granulometria, PS: Proteína solúvel; RAR: Redução de açúcares redutores.

Analisando a Tabela 3, pode-se verificar que o ensaio 3, utilizando a umidade inicial de 70\% e a granulometria na faixa de 0,85 a $1,7 \mathrm{~mm}$ proporcionou maior produção de proteína solúvel, atingindo valores médios de 19,24\%. A Tabela 4 apresenta os efeitos e valores de p para os fatores umidade inicial e granulometria do meio de cultivo para a resposta proteína solúvel.

Tabela 4- Estimativa dos efeitos e valores de p para a resposta proteína solúvel.

\begin{tabular}{lcc}
\hline & Efeito & Valor de p \\
\hline Média & 17,23 & 0,0000 \\
Umidade & 2,64 & 0,0019 \\
Granulometria & $-1,12$ & 0,0374 \\
Umidade X Granulometria & $-1,03$ & 0,0512 \\
\hline
\end{tabular}

Analisando a Tabela 4, verifica-se que as variáveis umidade inicial e granulometria, apresentaram efeito significativo $(\mathrm{p}<0,05)$ sobre a produção de proteína solúvel. A análise dos efeitos isolados demonstra que a utilização da umidade em seu nível superior (70\%) aumenta em média 2,64\% o conteúdo de proteína solúvel no bagaço de maçã. Já para a variável granulometria, esta aumenta em média $1,12 \%$ o conteúdo de proteína solúvel quando utilizado o nível inferior $(0,85$ a $1,7 \mathrm{~mm})$.

\section{Conclusão}

Maiores quantidades de proteína solúvel foram obtidas utilizando a uréia como fonte de nitrogênio na concentração de $5 \%(\mathrm{p} / \mathrm{p})$, umidade inicial de $70 \%$ e a granulometria na faixa de 0,85 a 1,70mm, produzindo 19,24\% de proteína solúvel no bagaço de maçã, aumentando em 2,5 vezes sue conteúdo protéico. 


\begin{abstract}
In this work apple pomace was used as substrate for the production of single cell protein in solid state fermentation with filamentous fungi Gongronella butleri CCT4274, for enrichment of this residue. The solid state fermentation, after studying the influence of adding nitrogen sources, initial moisture and granulometry over the protein production, promoted an increase of more than 2,5 fold in the protein content, which produced $19,24 \%$ of soluble protein in the best culture media: $5 \%$ $(\mathrm{w} / \mathrm{w})$ urea as a nitrogen source, initial moisture of $70 \%$ and granulometry in the strip from 0,85 to $1,70 \mathrm{~mm}$.
\end{abstract}

Keywords: apple pomace; soluble protein; solid state fermentation (SSF).

\title{
5. Referências
}

ANUPAMA; RAVINDRA, P. Value-added food: Single cell protein. Biotechnology Advances. v. 18, p.459-479, 2000 .

AOAC. Association of Official Analytical Chemists. Official Methods of Analysis. 15. ed. Arlington: AOAC, 1995. $2 \mathrm{v}$.

BALASUBRAMANIEM, A. K.; NAGARAJAN, K. V.; PARAMASAMY, G. Optimization of media for $\beta$ fructofuranosidase production by Aspergillus niger in submerged and solid state fermentation. Process Biochemistry. v. 36, p. 1241-1247, 2001.

BEROVIC, M.; OSTROVERSNIK, H. Production of Aspergillus niger pectolytic enzymes by solid state bioprocessing of apple pomace. Journal of Biotechnology. V.53, p.47-53. 1997.

DEL BIANCHI, V. L.; MORAEWS, I. O.; CAPALBO, D. M. F. Fermentação em Estado Sólido. In: SCHMIDELL, W. et al. (Coords). Biotecnologia industrial. v. 2. São Paulo: Edgard Blücher, 2001, 541p.

LOWRY, O. H.; ROSEBROUGH, N. J.; FARR, A. L. Protein measurement with the Folin Phenol reagent. Journal of Biological Chemistry, v. 193, p. 265-275, 1951.

MARTINS, E. S.; SILVA, D.; DA SILVA, R.; GOMES, E. Solid state production of thermostable pectinases from thermophilic Thermoascus aurantiacus. Process Biochemistry. v. 37, p. 949-954, 2002.

MILLER, G. L. Use of dinitrosalicilic acid reagent for determination of reducing sugar. Analytical Chemistry, v. 31, 9. 426-428, 1959.

VILLAS-BÔAS, S. G.; ESPÓSITO, E.; MITCHELL, D. A. Microbial of lignocellulosic residues for production of animals feeds. Animal feed Science and Technology. v.98, p.1-12. 2002.

\section{Primeiro autor:}

Nome completo: Francielo Vendruscolo

Filiação institucional: Universidade Federal de Santa Catarina - UFSC

Função ou cargo ocupado:

Endereço completo para correspondência (bairro, cidade, estado, país e CEP): Departamento de Engenharia Química e Engenharia de Alimentos, Centro Tecnológico-CTC, Caixa Postal 476, CEP: 88040-900, Florianóplis - SC.

e-mail: francielo@enq.ufsc.br 